\title{
A problemática dos organismos geneticamente modificados e a formação científica do cidadão comum: um estudo com manuais escolares de Ciências Naturais do $9^{\circ}$ ano adotados em Portugal
}

\author{
The genetically modified organisms issue \\ and citizen science education: a study of natural sciences \\ textbooks for $9^{\text {th }}$ grade adopted in Portugal
}

Luís Dourado $^{1}$ • Luís Matos ${ }^{2}$

\begin{abstract}
Resumo: Uma das aplicações da biotecnologia são os organismos geneticamente modificados (OGM), os quais têm uma utilização cada vez maior, apresentando vantagens, mas, também, sendo referidos como organismos potencialmente perigosos. Correspondendo a esses factos, os manuais de ciências dedicam algumas das suas páginas à biotecnologia, sendo os OGMs um dos aspetos focados. Nesse sentido e considerando a importância que o manual escolar tem na educação em ciências, procedemos a um estudo que envolveu a análise dos manuais escolares de ciências naturais do $9^{\circ}$ ano adotados em Portugal, na parte respeitante aos OGMs. Neste estudo verificou-se que os manuais nem sempre apresentam a informação correta e necessária, de forma adequada, e que nem sempre lhe dão o devido destaque. Dado que a nossa investigação revela a existência de falhas ao nível dos manuais, as conclusões obtidas podem contribuir para uma melhoria dos mesmos e, consequentemente, da qualidade da educação em ciências.

Palavras-chave: Organismos Geneticamente Modificados. OGM. Manual escolar. Educação em ciências.

Abstract: One of the applications of biotechnology is genetically modified organisms (GMOs), which have an increasing use, with many advantages, but are also being referred to as potentially dangerous organisms. Regarding these facts, science textbooks devote some of their pages to biotechnology, GMOs being one of the aspects focused on. Thus, considering the importance of the textbook in science education, we carried out a study involving the analysis of Portuguese 9th grade science textbooks concerning GMOs. In this study it was found that the textbooks do not always have accurate and necessary information, and sometimes do not present it in an adequate way and don't give it proper importance. As our research reveals the existence of gaps in textbooks, our conclusions can help to improve them and, therefore, the quality of science education.
\end{abstract}

Keywords: Genetically Modified Organisms. GMO. Textbooks. Science education.

\footnotetext{
${ }^{1}$ Instituto de Educação, Universidade do Minho, 4710-057, Campus de Gualtar, Braga, Portugal. E-mail:

$<$ ldourado@ie.uminho.pt>

${ }^{2}$ Escola Básica 2,3 de Paço de Sousa, 4560-346 Penafiel, Portugal. E-mail: matosfilipe@hotmail.com
} 


\section{Introdução}

\section{O papel do manual escolar na educação em ciências}

Numa época em que, na educação em ciências, se verifica uma multiplicidade de suportes de ensino, nomeadamente os suportes informáticos e audiovisuais, o manual escolar continua a ocupar um lugar central (ROSEMAN; STERN; KOPPAL, 2010; SANTOS, 2001; SNYDER; BROADWAY, 2004), desempenhando vários papéis, uma vez que apresenta um conjunto de conhecimentos, auxilia na organização de aprendizagem e orienta o aluno na compreensão do mundo que o rodeia, contribuindo para o desenvolvimento de competências do aluno e não apenas para a transmissão de conhecimentos. (SANTOS, 2006).

O manual escolar tem, assim, uma função fortemente reguladora das práticas escolares, sociais e éticas, servindo de suporte de conhecimentos para alunos e professores e de elemento de ligação entre a escola e a família (SANTOS, 2001), consubstanciada numa determinada visão da sociedade, da história e da cultura (MORGADO, 2004).

Assim, podemos considerar que a formação científica do aluno depende muito do conteúdo do manual, quer em termos de informação, quer em termos de atividades propostas, ainda que, em alguns casos, o manual não seja seguido na íntegra (SANTOS, 2001).

Em Portugal, é a própria legislação, nomeadamente o Decreto-Lei nº 47/2006, de 28 de agosto (PORTUGAL, 2006), que reconhece, explicitamente, a relevância do manual como importante recurso didático-pedagógico ao nível da informação que veicula, das atividades que propõe e da avaliação das aprendizagens, sublinhando a importância de estudos como aquele que aqui apresentamos, em que fazemos uma análise crítica de manuais.

\section{O conteúdo dos manuais escolares}

Apesar da importância do manual na educação em ciências, há algumas evidências de que o manual escolar pode ter falhas no nível científico, e que pode reforçar ou, mesmo, induzir algumas concepções alternativas dos alunos (LEITE, 1999).

Apesar dessa importância, muitas vezes os textos são imprecisos, vagos ou incompletos (JOHNSEN, 1996); apresentam, também, os conceitos numa sequência que nem sempre é a mais correta (LEITE, 1999), havendo, ainda, textos que não referem determinadas ideias-chave, ou que as apresentam de forma dispersa, sem que haja um aumento progressivo de complexidade (STERN; ROSEMAN, 2004).

Deste modo, para além de se poderem reforçar ou induzir concepções alternativas nos alunos (LEITE, 1999; MARTÍNEZ-GARCIA; GIL-QUÝLEZ; OSADA, 2003), torna-se difícil para os alunos se focarem nas ideias principais e relacioná-las entre si (STERN; ROSEMAN, 2004).

Santos (2004) acrescenta, ainda, que o manual, para além de nem sempre estimular a existência de diferentes perspectivas da realidade, também nem sempre promove o desenvolvimento do espírito científico e a existência de debates capazes de permitir o desenvolvimento de competências argumentativas e de tomada de opções - aspectos importantes numa sociedade 
plural em que o cidadão não deve ficar subjugado às ideias dos outros ou aceitar de forma acrítica aquilo que lhe pretendem impor.

De igual modo, importa salientar que o manual nem sempre dedica o necessário espaço e destaque a aspectos fundamentais da formação dos alunos como pessoas e cidadãos, como: a inclusão de textos de divulgação científica (SANTOS, 2004), ou a abordagem de temas controversos (SNYDER; BROADWAY, 2004) e sociocientíficos (REIS, 2004), os quais surgem, consoante o manual, em secções especiais, apêndices ou quadros, no decorrer dos capítulos ou junto das atividades ou exercícios, o que pode significar uma desvalorização dos mesmos.

Pedrosa e Leite (2005) acrescentam, ainda, que muitos manuais têm uma insuficiente relação entre os temas que apresentam, o que dificulta a compreensão do carácter transversal de muitos problemas com que a humanidade atualmente se depara. Snyder e Broadway (2004) referem ainda que a relação entre o quotidiano do aluno e a abordagem feita nos manuais nem sempre é evidente.

Assim, torna-se evidente que o manual deve ser utilizado de forma crítica e flexível, de modo a facilitar a aprendizagem dos conteúdos científicos pelos alunos (LEITE, 1999).

\section{A biotecnologia nos manuais escolares de ciências}

Em relação a estudos que analisam temas de biotecnologia nos manuais escolares, apresentamos os de Martínez-Garcia, Gil-Quýlez e Osada (2003) e de Ferreira e Justi (2004).

Martínez-Garcia, Gil-Quýlez e Osada (2003) analisaram 34 manuais de biologia do ensino secundário, publicados em Espanha, entre 1997 e 2001, tendo verificado que, de um modo geral, os manuais não fazem ligações conceptuais importantes, tal como a seguir se exemplifica: muitos dos manuais abordam a temática do genoma humano, mas não associam a sequência do $\mathrm{ADN}$ ao património genético do indivíduo, nem consideram a sequência de nucleotídeos na molécula do ADN; muitos manuais não referem que o material genético é partilhado por todas as espécies e, como consequência, o ADN é transferível entre várias espécies e pode se expressar do mesmo modo. Martínez-Garcia, Gil-Quýlez e Osada (2003) consideram que a fragmentação da informação pode ser uma fonte de concepções alternativas, tendo em consideração que muito tem que ser aprendido na ausência de associações com outros conhecimentos. Aqueles autores sugerem a introdução de uma sequência lógica de conceitos, a qual deve ser adequada ao nível etário e académico dos alunos e aos objetivos dos programas de ensino em ciências.

No que diz respeito às aplicações da biotecnologia, Martínez-Garcia, Gil-Quýlez e Osada (2003) referem que, na agricultura, as mais referidas são as plantas tolerantes aos herbicidas ou resistentes aos insetos. Na medicina, aqueles autores consideram que os aspectos mais referidos são a produção de insulina, de hormona do crescimento, interferon e vacinas.

Em relação às implicações dos OGMs, segundo Martínez-Garcia, Gil-Quýlez e Osada (2003), as implicações da engenharia genética são referidas, muitas vezes, de forma desequilibrada em termos de vantagem/riscos. Para aqueles autores, o reforço dos riscos pode levar os alunos a terem uma opinião negativa em relação às aplicações da biotecnologia, sobretudo quando o seu nível de conhecimento é baixo.

Martínez-Garcia, Gil-Quýlez e Osada (2003) verificaram, ainda, que os OGMs são uma das aplicações da biotecnologia que os alunos têm mais dificuldade em compreender, pois nem sempre há explicitação da ligação entre a função dos genes e as caraterísticas do OGM. 
Noutro estudo, Ferreira e Justi (2004) analisaram manuais escolares brasileiros de química e de biologia, do Ensino Médio, para averiguar como as abordagens utilizadas por aqueles manuais contribuem para o estudo do ADN. Estes autores constataram que o estudo do ADN se resume a uma breve abordagem do modelo de estrutura molecular do ADN, muitas vezes, separado do estudo da genética e da hereditariedade.

Ferreira e Justi (2004) consideram que, muitas vezes, a biotecnologia é tratada em textos auxiliares, nos quais são apresentados apenas alguns aspectos simples de engenharia genética, sem que haja relação com a composição e estrutura do ADN e sem uma discussão sobre os princípios éticos implicados na biotecnologia.

\section{Metodologia}

\section{População e amostra}

Em relação ao estudo feito com manuais escolares, a população correspondeu aos manuais de $9^{\circ}$ ano, da disciplina de Ciências Naturais, editados em Portugal (anexo A).

A seleção desta população tem a ver com o facto de serem os manuais do $9^{\circ}$ ano, da disciplina de Ciências Naturais, os únicos do Ensino Básico a abordarem os OGMs.

O facto de os objetivos deste estudo permitirem trabalhar com todos os manuais tem a vantagem de a população-alvo ser igual à amostra, o que é positivo em termos de generalização de resultados, evitando-se assim possíveis erros de amostragem, isto é, que a amostra tenha características diferentes da população-alvo (GALL; GALL; BORG, 2003).

\section{Técnica e instrumento de recolha de dados}

Os manuais foram analisados por meio da técnica de análise de conteúdo, a partir da qual foi preenchida uma grelha em que se cruzam as categorias de análise de cada dimensão (linhas) com os manuais em apreciação (colunas). A grelha foi elaborada pelo investigador, e sujeita a validação de conteúdo (GALL; GALL; BORG, 2003) por especialistas em educação em ciências. Com esta validação, pretendeu-se assegurar que as dimensões de análise permitem obter informação necessária, suficiente, válida e fiável (KETELE; ROEGIERS; BRITO, 1993).

A grelha de análise dos manuais incluiu as seguintes dimensões: conceito de OGM; relação dos OGMs com organismos transgênicos; relação dos OGMs com outros temas ou assuntos; exemplos de OGMs mencionados; situação dos OGMs em Portugal e no mundo; enquadramento legal dos OGMs; possíveis vantagens do uso dos OGMs, e potenciais riscos do uso dos OGMs nos domínios ambiental, de saúde e económico; atividades propostas pelos manuais; recurso a outras fontes de informação sobre OGMs; relação entre as imagens e as concepções dos alunos; reações aos OGMs por parte de grupos sociais implicados neles; monitorização dos eventuais riscos dos OGMs; perspectiva futura de utilização dos OGMs. 


\section{Recolha e tratamento de dados}

No processo de recolha de dados, o investigador elaborou a grelha referida na secção 'técnica e instrumento de recolha de dados' e sujeitou-a a validação. Na recolha de dados, o investigador aplicou a grelha de análise aos manuais por duas vezes, em idênticas condições, de modo a reduzir possíveis erros inerentes à subjetividade do investigador.

Os dados obtidos na análise de manuais foram tratados de modo a comparar os manuais entre si, em relação a cada dimensão de análise.

\section{Resultados}

No estudo com manuais escolares, analisámos os manuais de ciências naturais do $9^{\circ}$ ano, editados em Portugal, em relação aos OGMs, segundo dimensões e categorias de análise previamente estabelecidas e validadas por especialistas em educação.

Da análise dos referidos manuais, constatou-se que o número de páginas dedicado a este assunto é de quatro páginas nos manuais M3 e M5, três páginas nos manuais M7 e M4, e até duas páginas nos restantes manuais, e que nelas existem texto informativo, imagens e atividades propostas. O reduzido espaço dedicado aos OGMs vai ao encontro a trabalhos de vários autores, nomeadamente quando referem que os manuais nem sempre dão o espaço ou o destaque necessários a temas controversos (SNYDER; BROADWAY, 2004) e sociocientíficos (REIS, 2004).

Nos quadros seguintes, registram-se os resultados da análise de manuais relativamente a: conceito de OGM e suas relações com os transgênicos e com outros conceitos e assuntos (Quadro 1); exemplos de OGMs apresentados pelos manuais (Quadro 2); os OGMs em Portugal e no mundo (Quadro 3); implicações dos OGMs (Quadro 4), especificando-se as mesmas a nível ambiental (Quadro 5), de saúde (Quadro 6) e económico (Quadro 7); atividades propostas e recursos sugeridos (Quadro 8); imagens utilizadas (Quadro 9); reações de diferentes grupos sociais perante os OGMs, monitorização e perspectiva futura (Quadro 10).

\section{O conceito de organismo geneticamente modificado e suas relações com outros conceitos e conteúdos}

No Quadro 1, assinalamos o modo como os sete manuais se referem ao conceito de OGM, como o relacionam com o conceito de transgênico e com outros temas ou assuntos.

No que diz respeito à definição de OGM e sua relação com o conceito de transgênico, apenas os manuais M1, M3 e M5 apresentam a definição correta do que é um OGM, dando a ideia de que um OGM é um 'ser vivo cuja informação genética é manipulada'. Os manuais M7 e M2 apenas referem o significado do acrónimo OGM e o manual M6 não faz referência ao termo OGM, utilizando o termo 'transgênico'. O manual M5 descreve o processo de obtenção de OGMs, mas refere apenas esse acrónimo, não o definindo.

Quanto à relação entre OGM e transgênico, nenhum dos manuais estabelece a relação correta, uma vez que nenhum dos manuais transmite a ideia de que um transgênico é qualquer organismo que teve sua constituição genética alterada pela introdução de um ou mais genes de 
Dourado, L.; Matos, L.

um outro organismo, em geral de uma outra espécie (CORAZZA-NUNES et al., 2007), e que os OGM podem ser modificados de outra forma, como a supressão de genes, por exemplo. Os manuais M7, M2, M4 e M5 consideram-nos sinónimos e, na mesma linha de pensamento, o manual M6, que não faz referência ao termo OGM, utiliza o termo 'transgênico' em sua substituição. Quanto ao manual M1, não relaciona corretamente aqueles conceitos pois refere que os 'transgênicos são produtos alimentares obtidos a partir dos OGMs'. O Manual M3 não faz referência ao termo transgênico ao nível do texto.

Quadro 1. O conceito de OGM e suas relações com outros conceitos e assuntos

\begin{tabular}{|c|c|c|c|c|c|c|c|c|}
\hline \multirow[b]{2}{*}{ Dimensão } & \multirow[b]{2}{*}{ Categorias } & \multicolumn{7}{|c|}{ Manuais escolares } \\
\hline & & M1 & M2 & M3 & M4 & M5 & M6 & M7 \\
\hline \multirow{4}{*}{$\begin{array}{l}\text { Conceito } \\
\text { de OGM }\end{array}$} & Não faz referência ao conceito de OGM & & & & & & $X$ & \\
\hline & Refere o acrónimo OGM & & & & & $X$ & & \\
\hline & Refere o significado do acrónimo OGM & & $\mathrm{X}$ & $X$ & & & & $x$ \\
\hline & $\begin{array}{l}\text { Define corretamente Organismo Geneticamente } \\
\text { Modificado }\end{array}$ & $x$ & & & & $x$ & & \\
\hline \multirow{5}{*}{$\begin{array}{l}\text { Relação dos } \\
\text { OGMs com } \\
\text { organismos } \\
\text { transgênicos }\end{array}$} & $\begin{array}{l}\text { Não apresenta o conceito de organismo } \\
\text { transgênico }\end{array}$ & & & $\mathrm{X}$ & & & & \\
\hline & $\begin{array}{l}\text { Apresenta o conceito de organismo transgênico, } \\
\text { mas não o relaciona com o de OGM }\end{array}$ & & & & & & $\mathrm{X}$ & \\
\hline & $\begin{array}{l}\text { Apresenta OGM como sinónimo de organismo } \\
\text { transgênico }\end{array}$ & & $\mathrm{X}$ & & $\mathrm{X}$ & $x$ & & $x$ \\
\hline & $\begin{array}{l}\text { Distingue corretamente OGM de organismo } \\
\text { transgênico }\end{array}$ & & & & & & & \\
\hline & $\begin{array}{l}\text { Distingue incorretamente OGM de organismo } \\
\text { transgênico }\end{array}$ & $\mathrm{X}$ & & & & & & \\
\hline \multirow{3}{*}{$\begin{array}{l}\text { Relação de } \\
\text { OGMs com } \\
\text { outros temas } \\
\text { ou assuntos }\end{array}$} & $\begin{array}{l}\text { Relaciona OGMs com assuntos do quotidiano } \\
\text { dos alunos }\end{array}$ & $x$ & $\mathrm{X}$ & $x$ & $\mathrm{X}$ & $x$ & $\mathrm{x}$ & $x$ \\
\hline & $\begin{array}{l}\text { Relaciona OGMs com conteúdos de outras } \\
\text { disciplinas }\end{array}$ & $\mathrm{X}$ & $\mathrm{X}$ & & & & & $x$ \\
\hline & $\begin{array}{l}\text { Relaciona OGMs com conteúdos de outras } \\
\text { unidades didáticas da própria disciplina }\end{array}$ & $x$ & $\mathrm{X}$ & $x$ & $\mathrm{X}$ & $x$ & $x$ & $x$ \\
\hline
\end{tabular}

X - Presença

Fonte: Elaborado pelos autores.

A este propósito, é de referir que a equivalência entre os conceitos de OGM e de transgênico, evidenciada em cinco dos sete manuais, é uma concepção encontrada por Corazza-Nunes et al. (2007) e por Pedrancini et al. (2007) em alunos do Ensino Médio e universitário do Brasil, e vai ao encontro das ideias de Leite (1999) e de Stern e Roseman (2004), quando referem que a informação que o manual apresenta nem sempre é correta, do ponto de vista científico. 
No que diz respeito à ligação ao quotidiano dos alunos, apesar de todos os manuais relacionarem os OGMs com aspectos familiares aos alunos - nomeadamente, quando referem à produção de vacinas, de hormonas ou de insulina por microrganismos GM, ou quando apresentam exemplos de produtos conhecidos dos alunos (como o milho e o tomate) -, fazem-no com limitações, pois referem a sua existência, mas, raramente, explicitam que esses organismos podem já fazer parte do quotidiano dos alunos, o que confirma ideias de Pedrosa e Leite (2005), quando referem o tratamento excessivamente disciplinar e a insuficiente ligação ao quotidiano dos alunos dado pelos manuais a vários assuntos.

A articulação dos OGMs com outros conteúdos da própria disciplina é também limitada. Com exceção do manual M5, todos os manuais referem que os OGMs podem ter implicações ao nível do equilíbrio dos ecossistemas, mas fazem-no de forma vaga referindo escassas implicações (redução da poluição causada pelo uso de herbicidas e de pesticidas; possível contaminação de variedades não-GM por variedades GM).

Em relação à articulação com conteúdos da área da genética, os manuais M7, M4 e M5 relacionam os OGMs com conceitos básicos de genética, nomeadamente, quando apresentam um esquema que ilustra e explica a transferência de um gene presente no ADN de um organismo para o ADN de outro organismo. No entanto, entendemos que estes esquemas são de difícil compreensão para os alunos pois, para além do aspeto gráfico, usam termos pouco familiares, como, por exemplo, plasmídeo, e fazem referência a processos demasiado complexos para este nível etário.

Quanto à articulação com conteúdos de outras disciplinas, os manuais M1, M7 e M2 referem que os OGMs podem contribuir para atenuar a fome em várias regiões do mundo, o que se pode associar ao ensino da temática na disciplina de geografia, mas fazem-no apenas a pontuar esta temática, de forma vaga e sem desenvolvimento, não referindo de que modo os OGMs podem ser um recurso a utilizar no atenuar daquele problema e nem as implicações colaterais que isso pode ter a nível social, político ou económico.

Em síntese, podemos considerar que nem todos os manuais definem, corretamente, o que são OGMs ou transgênicos, o que contribui para que a aprendizagem dos conceitos não seja correta nem a relacionação entre eles.

Apesar de se estabelecer alguma ligação ao quotidiano dos alunos, nomeadamente por meio dos exemplos de OGMs dados, raramente se explicita que os alunos podem estar a consumir esses OGMs e que estão sujeitos às suas implicações. Por outro lado, a articulação entre esta temática e outras temáticas da disciplina ou de outras disciplinas é limitada.

\section{Exemplos de organismos geneticamente modificados}

No que concerne aos exemplos de OGMs apresentados nos manuais (Quadro 2), eles são variados, havendo exemplos de plantas, animais e microrganismos GM, e diferem de manual para manual.

Relativamente aos exemplos de plantas GM e tal como se constata no Quadro 2: o milho resistente a pragas é o exemplo mais comum, aparecendo em todos os manuais, com exceção do M5; o 'arroz dourado' aparece em três dos manuais; o algodão resistente a pragas e o tomate são exemplos que aparecem em dois manuais. Todos os outros exemplos de plantas GM aparecem apenas num único manual. 
A propósito dos exemplos de plantas GM, e relacionando-os com as três gerações de OGMs referidas por Fernandez-Cornejo e Caswell (2006), constata-se que eles são maioritariamente OGMs pertencentes à primeira geração de OGMs, ou seja, a variedade GM apresentada tem características reforçadas em relação à variedade não-GM, como a resistência a pragas ou a tolerância a herbicidas. As exceções são o ‘arroz dourado’ (manual M1), um OGM pertencente à segunda geração, ou seja, tem um maior valor nutricional do que a variedade não-GM, e a banana GM produtora de vacinas (manual M7), um OGM pertencente à terceira geração, em que a variedade GM produz fármacos ou sintetiza novos produtos.

Quadro 2. Exemplos de OGMs apresentados nos manuais

\begin{tabular}{|c|c|c|c|c|c|c|c|c|}
\hline \multirow[b]{2}{*}{ Dimensão } & \multirow[b]{2}{*}{ Categorias } & \multicolumn{7}{|c|}{ Manuais escolares } \\
\hline & & M1 & M2 & M3 & M4 & M5 & M6 & M7 \\
\hline \multirow{13}{*}{$\begin{array}{c}\text { Exemplos } \\
\text { de OGMs } \\
\text { mencionados }\end{array}$} & Milho resistente a pragas & $X$ & $\mathrm{X}$ & $\mathrm{X}$ & $\mathrm{X}$ & & $\mathrm{X}$ & $x$ \\
\hline & Soja resistente a pragas & $x$ & & & & & & \\
\hline & Algodão resistente a pragas & $X$ & & $\mathrm{X}$ & & & & \\
\hline & Arroz dourado & $\mathrm{X}$ & $\mathrm{X}$ & & & $X$ & & \\
\hline & Tomate com amadurecimento retardado & & & $\mathrm{X}$ & & & $\mathrm{X}$ & \\
\hline & Banana produtora de vacinas & & & & & & $x$ & \\
\hline & Morango com amadurecimento retardado & & & & & & & $x$ \\
\hline & $\begin{array}{l}\text { Galinhas que põem ovos com proteínas de } \\
\text { combate a certas formas de cancro }\end{array}$ & & & & & & $x$ & \\
\hline & Porco para xenotransplantes & & & & & & & $x$ \\
\hline & Porco produtor de ómega-3 & $\mathrm{x}$ & & $x$ & & & & \\
\hline & Salmão GM & & & & & $\mathrm{X}$ & & \\
\hline & Escherichia coli produtora de insulina & $X$ & & $X$ & $\mathrm{X}$ & & & $x$ \\
\hline & Microrganismos produtores de vacinas & & & & & & $x$ & $x$ \\
\hline
\end{tabular}

X-Presença

Fonte: Elaborado pelos autores.

Em relação aos exemplos de animais GM, a maioria pertence à terceira geração de OGMs referida por Fernandez-Cornejo e Caswell (2006): o porco GM aparece nos manuais M1, M7 e M3 com diferentes propósitos, ou seja, nos manuais M1 e M3, o exemplo é de porcos produtores de ómega-3 (ácidos gordos insaturados e, por isso, não tão prejudiciais à saúde como os ácidos gordos de porcos não-GM); e, no manual M7, refere-se à existência de porcos doadores de órgãos (presumindo-se que se destinem a xenotransplantes). O manual M6 apresenta um outro exemplo de animal GM pertencente à terceira geração, galinhas capazes de produzirem ovos que contêm substâncias de controlo de algumas formas de cancro. A exceção é o salmão 
GM (manual M5), pertencente à primeira geração de OGM, o qual é capaz de crescer mais rapidamente do que a variedade não-GM.

Quanto aos exemplos de microrganismos GM, os manuais M1, M7 e M4 referem que a Escherichia coli GM é capaz de produzir insulina humana; enquanto o manual M3 refere que aquela bactéria GM produz substâncias necessárias ao tratamento de certas doenças, como a diabetes. Ambos os organismos são pertencentes à terceira geração de OGMs referida por Fernandez-Cornejo e Caswell (2006), ou seja, produzem fármacos ou novos produtos. Daqueles manuais, os manuais M1 e M4 acrescentam que essa capacidade foi adquirida pela introdução do gene humano que codifica a síntese da insulina, no genoma da bactéria.

Ainda em relação a microrganismos GM e para além da referência à Escherichia coli GM, o manual M7 faz referência a 'bactérias produtoras de vacinas'; e o manual M6 faz referência ao facto de se utilizarem microrganismos GM produtores de vacinas e hormonas.

Em síntese, constatamos que os exemplos apresentados pelos manuais são diversos e ilustram mais as potencialidades dos OGMs do que a ligação ao quotidiano dos alunos.

Os exemplos de plantas GMs são mais numerosos e, maioritariamente, pertencentes à primeira geração de OGMs. Os exemplos de animais e de microrganismos são, sobretudo, de OGMs pertencentes à terceira geração.

\section{Os organismos geneticamente modificados em Portugal e no mundo}

Outros aspectos relacionados com os OGMs são a 'situação dos OGM em Portugal e no mundo’ e o 'enquadramento legal dos OGMs', os quais apresentamos no Quadro 3. Optamos por apresentar estas dimensões em conjunto, uma vez que estão relacionadas, sobretudo, com aspectos económicos e políticos.

Quadro 3. Os OGMs em Portugal e no mundo

\begin{tabular}{|c|c|c|c|c|c|c|c|c|}
\hline \multirow[b]{2}{*}{ Dimensão } & \multirow[b]{2}{*}{ Categorias } & \multicolumn{7}{|c|}{ Manuais escolares } \\
\hline & & M1 & M2 & M3 & M4 & M5 & M6 & M7 \\
\hline \multirow{3}{*}{$\begin{array}{l}\text { Os OGMs em } \\
\text { Portugal e no } \\
\text { mundo }\end{array}$} & Refere os OGMs em Portugal & $x$ & & & & & & $x$ \\
\hline & Refere os OGMs na Europa & & & & & & & \\
\hline & Refere os OGMs no mundo & & & & & & & \\
\hline \multirow{2}{*}{$\begin{array}{c}\text { Enquadramento } \\
\text { legal dos } \\
\text { OGMs }\end{array}$} & $\begin{array}{l}\text { Menciona os normativos legais europeus } \\
\text { relativos aos OGMs }\end{array}$ & & & & & & & \\
\hline & $\begin{array}{l}\text { Menciona os normativos legais portugueses } \\
\text { relativos aos OGMs }\end{array}$ & & & & & & & $x$ \\
\hline
\end{tabular}

X-Presença

Fonte: Elaborado pelos autores.

No que diz respeito à situação dos OGMs em Portugal, apenas os manuais M1 e M7 dedicam espaço a esse assunto, ao apresentarem as áreas de cultivo de milho GM em Portugal. Em relação a outros aspetos relacionados com a produção e comercialização dos OGMs em Portugal, não há qualquer referência nestes manuais. 
Este facto pode dar resposta a dois dos resultados obtidos no estudo de Santos (2006) quando refere que a maioria dos alunos não sabe se é legal o cultivo de OGMs em Portugal e que eles desconhecem se existem OGMs comercializados no país.

Em relação ao enquadramento legal dos OGMs, este aspeto só é referido no manual $\mathrm{M} 7$, nomeadamente quando faz referência à rotulagem obrigatória, em Portugal, de produtos alimentares com mais de 0,5\% de OGMs.

Nenhum dos manuais faz qualquer referência à situação dos OGMs fora de Portugal, quer em termos de produção, quer em termos de utilização ou de regulamentação.

\section{Implicações dos organismos geneticamente modificados}

No Quadro 4, apresentamos os tipos de vantagens e desvantagens dos OGMs existentes nos manuais. De sua análise, constata-se que quase todos os manuais apresentam vantagens e desvantagens dos OGMs a nível da saúde e a nível ambiental. Em menor número, os manuais referem vantagens e riscos dos OGMs a nível económico.

Quadro 4. Implicações dos OGMs

\begin{tabular}{|c|c|c|c|c|c|c|c|c|}
\hline \multirow[b]{2}{*}{ Dimensão } & \multirow[b]{2}{*}{ Categorias } & \multicolumn{7}{|c|}{ Manuais escolares } \\
\hline & & M1 & M2 & M3 & M4 & M5 & M6 & M7 \\
\hline \multirow{3}{*}{$\begin{array}{c}\text { Possíveis } \\
\text { vantagens do } \\
\text { uso dos OGMs }\end{array}$} & Vantagens a nível ambiental & $\mathrm{x}$ & $\mathrm{X}$ & $x$ & $\mathrm{X}$ & & $x$ & $x$ \\
\hline & Vantagens a nível da saúde & $\mathrm{X}$ & $\mathrm{X}$ & $\mathrm{X}$ & $\mathrm{X}$ & $\mathrm{X}$ & $\mathrm{X}$ & $x$ \\
\hline & Vantagens a nível económico & $\mathrm{X}$ & $X$ & & & & $X$ & $x$ \\
\hline \multirow{3}{*}{$\begin{array}{l}\text { Potenciais } \\
\text { riscos do uso } \\
\text { dos OGMs }\end{array}$} & Riscos a nível ambiental & & $x$ & $x$ & $x$ & $x$ & & $x$ \\
\hline & Riscos a nível da saúde & $x$ & $x$ & $x$ & $x$ & $x$ & & $x$ \\
\hline & Riscos a nível económico & $x$ & $\mathrm{X}$ & & & & & \\
\hline
\end{tabular}

X - Presença

Fonte: Elaborado pelos autores.

No entanto, verifica-se que, de uma forma geral, aquelas vantagens e riscos são apresentados de forma pontual, ilustrativa, genérica, desequilibrada e com baixa estimulação da indagação, uma vez que surgem no manual a título exemplificativo, com informação vaga e aparentemente comprovada, muitas vezes, sem que haja equidade entre vantagens e riscos, havendo, nestes casos, maior ênfase nas vantagens do que nos riscos.

Atendendo à diversidade de exemplos de vantagens/riscos nos diferentes domínios, optamos por apresentar os resultados em diferentes quadros. Assim, no Quadro 5, apresentamos as implicações dos OGMs a nível ambiental; no Quadro 6, as implicações dos OGMs a nível da saúde, e, no Quadro 7, as implicações dos OGMs a nível económico. 
A problemática dos organismos ...

Quadro 5. Implicações dos OGMs a nível ambiental

\begin{tabular}{|c|c|c|c|c|c|c|c|c|}
\hline \multirow[b]{2}{*}{ Dimensão } & \multirow[b]{2}{*}{ Categorias } & \multicolumn{7}{|c|}{ Manuais escolares } \\
\hline & & M1 & M2 & M3 & M4 & M5 & M6 & M7 \\
\hline $\begin{array}{l}\text { Vantagens } \\
\text { dos OGMs }\end{array}$ & $\begin{array}{l}\text { Diminuição da utilização de herbicidas e de } \\
\text { pesticidas }\end{array}$ & $x$ & $x$ & $x$ & $x$ & & $x$ & $x$ \\
\hline \multirow{4}{*}{$\begin{array}{l}\text { Riscos dos } \\
\text { OGMs }\end{array}$} & $\begin{array}{l}\text { Transmissão da caraterística GM a variedades } \\
\text { não-GM }\end{array}$ & & & $x$ & & & & $x$ \\
\hline & Redução da biodiversidade & & $x$ & & & & & \\
\hline & $\begin{array}{l}\text { Aquisição de resistência, por parte de bactérias, } \\
\text { insetos ou ervas daninhas }\end{array}$ & & $x$ & $x$ & & & & \\
\hline & Impacte ambiental negativo, sem especificar qual & & & & $x$ & $x$ & & \\
\hline
\end{tabular}

X-Presença

Fonte: Elaborado pelos autores.

A nível ambiental, com exceção do manual M5, os manuais referem que o recurso aos OGMs tem como vantagem reduzir a utilização de herbicidas e de pesticidas, na agricultura, mas sem explicarem o seu impacto no ecossistema. Quanto a desvantagens, os manuais não referem sempre a mesma: os manuais $\mathrm{M} 7$ e M3 referem a possibilidade de o material genético de uma variedade GM poder ser transmitido a uma variedade não-GM, sem explicar como (o manual M7 ainda refere o termo polinização, mas não o explica); o manual M2 refere que as espécies transgénicas podem contribuir para a redução da biodiversidade, mas também não explica por quê; os manuais M2 e M3 dizem que as bactérias e os insetos podem adquirir resistências (mas o manual M2 não diz a quê; o manual M3 diz que essa resistência dá-se em relação às toxinas produzidas pelas espécies GM); O manual M3 refere a capacidade de as ervas daninhas se tornarem resistentes aos herbicidas; os manuais M4 e M5 falam apenas num possível impacte ambiental, mas não especificam que impacte será esse.

A nível de saúde (Quadro 6), as vantagens apresentadas pelos manuais estão muitas vezes associadas aos exemplos que apresentam, nomeadamente a produção de vacinas, de hormonas ou de insulina por microrganismos GM (manuais M1, M6, M7, M3 e M4); possibilidade de se efetuarem xenotransplantes a partir do porco (manual M7); produção de gorduras com melhor qualidade nutricional em porcos GM (manual M1); produção de ovos por galinhas GM, os quais contêm substâncias de controlo a certas formas de cancro (manual M6); plantas cujos frutos são portadores de vacinas, nomeadamente a banana portadora da vacina para a hepatite B (manual M5); alimentos com maior valor nutricional (M1, M2, M3, M4 e M5), tal como o arroz dourado (manual M2 e M5), batatas com maior teor de amido (manual M4) ou frutas e legumes com maior teor de vitamina A (manual M4).

Em relação às desvantagens da utilização dos OGMs no campo da saúde, os manuais M1, M2 e M3 fazem referência ao possível aparecimento de alergias a partir do consumo de OGMs; o manual M1 refere, ainda, a possibilidade de riscos, não provados, ao nível da reprodução e de danos em órgãos vitais; o manual M3 fala na possível resistência a antibióticos; os manuais M4 e M5 falam apenas na possibilidade de haver impacte na saúde, mas sem especificar qual. 
Dourado, L.; Matos, L.

Quadro 6. Implicações dos OGMs a nível da saúde

\begin{tabular}{|c|c|c|c|c|c|c|c|c|}
\hline \multirow[b]{2}{*}{ Dimensão } & \multirow[b]{2}{*}{ Categorias } & \multicolumn{7}{|c|}{ Manuais escolares } \\
\hline & & M1 & M2 & M3 & M4 & M5 & M6 & M7 \\
\hline \multirow{5}{*}{$\begin{array}{l}\text { Vantagens } \\
\text { dos OGMs }\end{array}$} & Produção de vacinas, hormonas ou de insulina & $\mathrm{X}$ & & $\mathrm{X}$ & $x$ & & $\mathrm{X}$ & $\mathrm{X}$ \\
\hline & Possibilidade de xenotransplantes a partir do porco & & & & & & & $X$ \\
\hline & Produção de alimentos com maior valor nutricional & $\mathrm{X}$ & $\mathrm{X}$ & $\mathrm{X}$ & $\mathrm{X}$ & $\mathrm{X}$ & & \\
\hline & $\begin{array}{l}\text { Produção de alimentos portadores de vacinas (ex. } \\
\text { banana) }\end{array}$ & & & & & $\mathrm{X}$ & & \\
\hline & $\begin{array}{l}\text { Ovos contendo substâncias de controlo de certas } \\
\text { formas de cancro }\end{array}$ & & & & & & $\mathrm{X}$ & \\
\hline \multirow{4}{*}{$\begin{array}{l}\text { Riscos } \\
\text { dos OGMs }\end{array}$} & Possível aparecimento de alergias & $\mathrm{x}$ & $x$ & $\mathrm{X}$ & & & & \\
\hline & $\begin{array}{l}\text { Possibilidade de danos a nível da reprodução e em } \\
\text { órgãos vitais }\end{array}$ & $\mathrm{X}$ & & & & & & \\
\hline & Resistência a antibióticos & & & $x$ & & & & \\
\hline & Risco para a saúde, mas sem especificar quais & & & & $\mathrm{X}$ & $\mathrm{X}$ & & \\
\hline
\end{tabular}

$\mathrm{X}$ - Presença

Fonte: Elaborado pelos autores.

No plano económico (Quadro 7), a propósito das vantagens dos OGMs apresentadas nos manuais, é referido o amadurecimento retardado dos frutos (manuais M6, M7 e M4 - o manual M6 refere o caso do tomate, enquanto o manual M7 refere o caso do morango); aumento na produção agrícola (manual M2); o facto de os OGMs poderem contribuir para atenuar o problema da fome no mundo (manuais M1 e M7).

Quadro 7. Implicações dos OGMs a nível económico

\begin{tabular}{|c|c|c|c|c|c|c|c|c|}
\hline \multirow[b]{2}{*}{ Dimensão } & \multirow[b]{2}{*}{ Categorias } & \multicolumn{7}{|c|}{ Manuais escolares } \\
\hline & & M1 & M2 & M3 & M4 & M5 & M6 & M7 \\
\hline \multirow{3}{*}{$\begin{array}{l}\text { Vantagens } \\
\text { dos OGMs }\end{array}$} & Amadurecimento retardado dos frutos, após colheita & & & & $\mathrm{X}$ & & $\mathrm{X}$ & $\mathrm{X}$ \\
\hline & Aumento da produção agrícola & & $\mathrm{X}$ & & & & & \\
\hline & Contribuição para atenuar a fome no mundo & $\mathrm{X}$ & & & & & & $\mathrm{X}$ \\
\hline \multirow{2}{*}{$\begin{array}{l}\text { Riscos } \\
\text { dos OGMs }\end{array}$} & $\begin{array}{l}\text { Dependência económica dos agricultores em } \\
\text { relação às empresas produtoras dos OGMs }\end{array}$ & $\mathrm{X}$ & & & & & & \\
\hline & Produção excedentária de alguns produtos & & $\mathrm{X}$ & & & & & \\
\hline
\end{tabular}

\section{$X$ - Presença}

Fonte: Elaborado pelos autores. 
Em relação às desvantagens dos OGMs a nível económico, o manual M1 alerta para o risco da dependência económica dos agricultores em relação às empresas produtoras de OGMs, e o manual M2, para a produção excedentária de alguns alimentos.

Todas estas características dos manuais ajudam a perceber que os alunos possam ter ideias vagas sobre estes temas, tal como foi detectado nos estudos de Corazza-Nunes et al. (2007) e Pedrancini et al. (2007), e convergem para as ideias de vários autores, nomeadamente: Santos (2004), quando refere que os manuais não estimulam a existência de diferentes perspectivas da realidade, nem promovem o desenvolvimento do espírito científico, nem a existência de debates; Megid Neto e Fracalanza (2003), quando defendem que os manuais consideram o aluno como um receptor passivo da informação fornecida e que esta é antropocêntrica; Martínez-Garcia, Gil-Quýlez e Osada (2003), quando estes referem que as implicações da engenharia genética são referidas, muitas vezes, de forma desequilibrada em termos de vantagem/riscos.

\section{Atividades propostas e recursos sugeridos pelos manuais}

No que concerne às atividades propostas pelo manual (Quadro 8), todos os manuais, à exceção do manual M6, propõem atividades de papel e lápis. Estas atividades são, maioritariamente, de tipo repetitivo e de reforço de aprendizagens. Este facto vai ao encontro às ideias de Martinez Losada et al. (1999) quando referem que, muitas vezes, as atividades são de baixo nível cognitivo e de mera confirmação, o que não fomenta o desenvolvimento de capacidades de análise ou de resolução de problemas, nem desafia os alunos a desenvolver o seu sentido crítico ou o raciocínio lógico.

Os manuais M1, M6, M3, M4 e M5 propõem, aos professores ou diretamente aos alunos, trabalhos de pesquisa, os quais têm elevado grau de abstração, são pouco dirigidos e de morosa discussão, o que pode dificultar a sua elaboração e a sua discussão. Após o trabalho de

Quadro 8. Atividades propostas e recursos sugeridos pelos manuais

\begin{tabular}{|c|c|c|c|c|c|c|c|c|}
\hline \multirow[b]{2}{*}{ Dimensão } & \multirow[b]{2}{*}{ Categorias } & \multicolumn{7}{|c|}{ Manuais escolares } \\
\hline & & M1 & M2 & M3 & M4 & M5 & M6 & M7 \\
\hline \multirow{5}{*}{$\begin{array}{c}\text { Atividades } \\
\text { propostas } \\
\text { aos alunos }\end{array}$} & Exercícios de papel e lápis & $x$ & $x$ & $x$ & $x$ & $x$ & & $x$ \\
\hline & Trabalho de pesquisa & $\mathrm{X}$ & & $\mathrm{x}$ & $x$ & $\mathrm{X}$ & $\mathrm{X}$ & \\
\hline & Debate & $x$ & & & & & $x$ & $x$ \\
\hline & Cartazes & & & & & & & \\
\hline & Apresentação de trabalhos & $X$ & & $x$ & $X$ & $x$ & $X$ & \\
\hline \multirow{3}{*}{$\begin{array}{c}\text { Recurso } \\
\text { a outras } \\
\text { fontes de } \\
\text { informação }\end{array}$} & Recurso à comunicação social & $\mathrm{X}$ & & & $x$ & & $\mathrm{x}$ & $x$ \\
\hline & Recurso à internet & $x$ & & & $x$ & & $x$ & \\
\hline & Livros temáticos & $\mathrm{X}$ & & & $x$ & & $x$ & \\
\hline
\end{tabular}


pesquisa, aqueles manuais recomendam que se proceda à apresentação dos mesmos, em sala de aula ou por intermédio de outro meio, como, por exemplo, o jornal escolar.

Em relação à consulta de outras fontes de informação, ela é estimulada nos manuais M1, M6 e M4 para a realização dos trabalhos de pesquisa, se bem que não explicitem quais. O manual M7 inclui uma imagem com alguns títulos de notícias de jornais como exemplo de outras fontes de informação.

Assim, podemos considerar que, de um modo geral, os manuais apresentam atividades de papel e lápis, usadas, sobretudo, como reforço da aprendizagem, não solicitando a opinião do aluno ou exigindo uma tomada de decisão; atividades de pesquisa pouco orientadas e apresentadas sem grande ênfase.

\section{Imagens veiculadas pelos manuais}

No Quadro 9, apresentamos a relação entre as imagens e as concepções dos alunos, uma vez que as imagens nem sempre são neutras, já que podem fomentar a construção de ideias corretas sobre os assuntos, mas, também, podem induzir ou reforçar concepções alternativas.

Em relação às imagens presentes nestes manuais, elas são, na sua maioria, apenas fotografias de exemplos de OGM. Deste modo, elas são essencialmente ilustrativas, ou seja, incluem uma legenda que descreve o que o leitor está a ver, mas que não acrescentam informação ao texto que as acompanha (POZZER; ROTH, 2003) e são neutras.

Quadro 9. Imagens apresentadas pelos manuais

\begin{tabular}{|c|c|c|c|c|c|c|c|c|}
\hline \multirow[b]{2}{*}{ Dimensão } & \multirow[b]{2}{*}{ Categorias } & \multicolumn{7}{|c|}{ Manuais escolares } \\
\hline & & M1 & M2 & M3 & M4 & M5 & M6 & M7 \\
\hline \multirow{3}{*}{$\begin{array}{c}\text { Relação } \\
\text { entre as } \\
\text { imagens } \\
\text { e as } \\
\text { concepções } \\
\text { dos alunos }\end{array}$} & "Neutra" & $\mathrm{X}$ & $\mathrm{X}$ & $\mathrm{X}$ & & & $\mathrm{X}$ & $\mathrm{x}$ \\
\hline & Suscetíveis de induzir conceçpões alternativas & $\mathrm{X}$ & & & $x$ & $\mathrm{X}$ & $\mathrm{X}$ & $\mathrm{x}$ \\
\hline & $\begin{array}{l}\text { Suscetíveis de fomentar a construção de ideias } \\
\text { corretas sobre os OGMs }\end{array}$ & & & & $\mathrm{X}$ & $x$ & & $x$ \\
\hline
\end{tabular}

X - Presença

Fonte: Elaborado pelos autores.

Os manuais M7, M4 e M5 possuem uma imagem que não é apenas ilustrativa, é uma imagem complementar, isto é, a imagem e a respetiva legenda acrescentam informação nova e relevante às informações presentes no texto que lhes está associado, facilitando a compreensão, pelos alunos, dos conceitos que estão a ser lecionados (POZZER; ROTH, 2003). Esta imagem consiste num esquema explicativo do processo de transferência de um gene de um organismo para outro, tornando este um OGM de tipo transgênico.

Esta imagem pode facilitar a construção do conhecimento pelo aluno em relação aos processos de obtenção de organismos transgênicos, pois mostra algo que é impossível de observar, o que é uma mais-valia das imagens, tal com consideram Leite e Afonso (2001). 
No entanto, esta imagem tem algumas limitações que podem induzir concepções alternativas, nomeadamente: o facto de aquele esquema ser um esquema simplificado; de apenas ser válido para organismos transgênicos, e não para todos os OGMs; a ausência de referências à fisiologia bacteriana; o tamanho relativo dos organismos e do material genético; a representação gráfica do material genético. Deste modo, o professor deve proceder de forma a que sejam explicitadas as relações representadas entre os diferentes elementos da imagem e assinaladas as limitações desta, tal como defendem Leite e Afonso (2001) quando referem que a análise crítica das imagens, pelo professor em conjunto com os alunos, é importante, pois permite a detecção de erros e identificar as limitações da imagem.

Assim, podemos considerar que a maioria das imagens diz respeito a exemplos de OGMs e são apenas ilustrativas. As únicas exceções são imagens que representam a produção de transgênicos, as quais, se, por um lado, evidenciam algo impossível de ver, por outro lado, apresentam limitações que devem ser enfatizadas pelo professor em conjunto com os alunos.

\section{Os organismos geneticamente modificados e a sociedade: reações, monitorização e perspectiva futura}

Em relação às reações de diferentes grupos sociais perante os OGMs, à monitorização e perspectiva futura dos OGMs (Quadro 10), o manual M7 refere a opinião de ambientalistas, de políticos e de cientistas sobre os transgênicos (que o manual considera como sinónimos de OGMs), referindo que os ambientalistas são contra os transgênicos; os políticos são a favor como medida de combate à fome; os cientistas estão divididos entre aqueles que os aceitam e aqueles que defendem que há muito por conhecer relativamente a estes organismos.

A monitorização dos eventuais riscos dos OGMs é referida pelos manuais M6 e M7, demonstrando que estas aplicações da Ciência devem ser acompanhadas pelos cidadãos face aos eventuais riscos que a utilização dos OGMs pode acarretar.

O manual M1 não faz qualquer referência à monitorização dos riscos dos OGMs, mas, em contraponto, propõe que os alunos assumam o papel de diversos grupos sociais, promovendo um debate em relação à produção de OGMs, nomeadamente de milho.

No que concerne à perspectiva futura de produção e utilização dos OGMs, os manuais M1 e M6 referem, de forma implícita, que há tendência para uma maior diversificação de OGMs e que a produção e comercialização de OGMs tenderá a aumentar. Os manuais M4 e M5 salientam o facto de a utilização de OGMs levantar problemas éticos.

No entanto, apesar destas referências, em nenhum dos manuais se verifica a articulação da opinião dos diferentes grupos sociais, com a monitorização dos OGMs ou com a projeção futura destes.

Podemos, assim, considerar que a relação existente entre os OGMs e a sociedade, ao nível das reações, monitorização e perspectiva futura, é pouco referida nos manuais, uma vez que a maioria dos manuais nem sequer contempla isso nas suas páginas. 
Dourado, L.; Matos, L.

Quadro 10. Reações de diferentes grupos sociais sobre os OGMs, monitorização e perspectiva futura dos OGMs

\begin{tabular}{|c|c|c|c|c|c|c|c|c|}
\hline \multirow[b]{2}{*}{ Dimensão } & \multirow[b]{2}{*}{ Categorias } & \multicolumn{7}{|c|}{ Manuais escolares } \\
\hline & & M1 & M2 & M3 & M4 & M5 & M6 & M7 \\
\hline \multirow{5}{*}{$\begin{array}{l}\text { Reações } \\
\text { aos OGMs }\end{array}$} & Cientistas & & & & & & & $\mathrm{X}$ \\
\hline & Políticos & & & & & & & $X$ \\
\hline & Cidadãos & & & & & & & \\
\hline & ONG & & & & & & & \\
\hline & Ambientalistas & & & & & & & $x$ \\
\hline \multirow{4}{*}{$\begin{array}{c}\text { Monitorização } \\
\text { dos eventuais } \\
\text { riscos dos } \\
\text { OGMs }\end{array}$} & Sociedade & & & & & & $X$ & $\mathrm{X}$ \\
\hline & Cientistas & & & & & & & \\
\hline & Políticos & & & & & & & \\
\hline & Cidadãos & & & & & & & \\
\hline \multirow{4}{*}{$\begin{array}{c}\text { Perspectiva } \\
\text { futura de } \\
\text { utilização dos } \\
\text { OGMs }\end{array}$} & Na saúde & & & & & & & \\
\hline & No ambiente & & & & & & & \\
\hline & Na economia & $X$ & & & & & $\mathrm{X}$ & \\
\hline & Nas questões éticas & & & & $\mathrm{X}$ & $\mathrm{X}$ & & \\
\hline
\end{tabular}

X-Presença

Fonte: Elaborado pelos autores.

\section{Conclusões}

As conclusões da nossa investigação resultam dos dados obtidos no estudo efetuado, em que analisámos o conteúdo dos manuais escolares de Ciências Naturais, $9^{\circ}$ ano, editados em Portugal, sobre os OGMs. Desse estudo constatámos que:

- os manuais dedicam poucas páginas aos OGMs e às suas implicações, aspeto que é comum a outros temas controversos (SNYDER; BROADWAY, 2004) e sociocientíficos (REIS, 2004);

- a propósito do conceito de OGM, apenas os manuais M1, M3 e M5 apresentam esse conceito cientificamente correto. Este facto confirma as ideias de Leite (1999) e de Stern e Roseman (2004), quando referem que a informação que o manual apresenta nem sempre é correta do ponto de vista científico;

- a relação dos OGMs com o quotidiano dos alunos, com outros temas ou assuntos é reduzida, o que vai ao encontro às ideias de Pedrosa e Leite (2005), quando referem que os manuais dão um tratamento excessivamente disciplinar aos assuntos, com insuficiente ligação ao quotidiano dos alunos; 
- a referência à situação dos OGMs em Portugal é limitada à área de cultivo do milho, e a referência à regulamentação dos OGMs está confinada à rotulagem obrigatória para produtos alimentares com mais de $0,5 \%$ de OGMs;

- quanto aos exemplos de OGMs, estes variam consoante o manual, sendo os mais frequentes de plantas e pertencentes à primeira geração de OGMs, ou seja, OGMs que apresentam características reforçadas em relação à variedade não-GM. Os exemplos de animais GM e de microrganismos GM são de organismos pertencentes à terceira geração de OGMs, isto é, OGMs produtores de fármacos ou que sintetizam novos produtos. Não foram encontrados exemplos de OGMs pertencentes à segunda geração, aqueles que têm um maior valor nutricional do que a variedade não-GM;

- no que concerne às vantagens e desvantagens dos OGMs, elas são apresentadas de forma pontual, ilustrativa, genérica e com baixa estimulação da indagação, sendo apresentadas mais como factos do que como elementos de debate, o que vai ao encontro às ideias de Santos (2004), quando refere que os manuais não estimulam a existência de diferentes perspectivas da realidade, nem promovem o desenvolvimento do espírito científico, nem a existência de debates;

- quanto às atividades propostas pelos manuais, todos eles, com exceção dos manuais M7 e M2 sugerem trabalho de pesquisa, com recurso a outras fontes de informação e apresentação final. No entanto, normalmente, as atividades de pesquisa propostas têm elevado grau de abstração, são pouco orientadas e de morosa discussão;

- as atividades de tipo papel e lápis são, maioritariamente, de tipo repetitivo e de reforço de aprendizagens, aspecto que, segundo Martinez Losada et al. (1999), não fomenta o desenvolvimento de capacidades de análise ou de resolução de problemas, nem desafia os estudantes a desenvolverem o seu sentido crítico ou o raciocínio lógico;

- em relação às imagens presentes nos manuais sobre este tema, elas são quase todas ilustrativas e referem-se a exemplos de OGMs, não acrescentando informação ao texto que as acompanha. A única imagem que não é meramente ilustrativa é um esquema explicativo da formação de transgênicos e surge nos manuais M7, M4 e M5; e, se por um lado, pode facilitar a construção do conhecimento; pelo aluno; em relação aos processos de obtenção de organismos transgênicos, por outro; tem limitações que podem induzir ou reforçar concepções alternativas do aluno. Este é um aspecto importante dos manuais pois, tal como referem Leite e Afonso (2001), muitas das concepções alternativas persistem durante o ensino das ciências, mesmo quando se adotam estratégias de tipo construtivista;

- apenas os manuais M6 e M7 fazem breve referência ao facto de a sociedade dever ter um papel ativo na monitorização dos riscos dos OGMs. No entanto, em nenhum dos manuais se verifica a articulação da opinião dos diferentes grupos sociais, com a monitorização dos OGMs ou com a perspectiva futura destes.

\section{Sugestões para futuras investigações}

Para finalizar este trabalho, apresentamos sugestões para futuras investigações, as quais podem esclarecer aspectos dos manuais que poderão não ter sido completamente esclarecidos no estudo efetuado. Assim, sugerimos que se façam estudos semelhantes em relação a outros temas de âmbito sociocientífico, quer estejam relacionados com a biotecnologia, como a clo- 
nagem e a terapia genética, ou não, como o desenvolvimento sustentável (energia, medidas de combate à poluição, gestão de recursos, incineração de resíduos) ou as radiações a que estamos expostos (radiação solar, radiação dos telefones celulares).

\section{Referências}

CORAZZA-NUNES, M. J. et al. O que conhecem os estudantes do ensino médio e ensino superior sobre transgênicos. In: ENCONTRO NACIONAL DE PESQUISA EM EDUCAÇÃO EM CIÊNCIAS, 6., 2007, Florianópolis. Anais... [S.l.]: Associação Brasileira de Pesquisa em Educação em Ciências, 2007. p. 1-12.

FERNANDEZ-CORNEJO, J.; CASWELL, M. The first decade of genetically engineered crops in the United States. Economic Information Bulletin, Washington, n. 11, p. 1-30, Apr. 2006.

FERREIRA, P. F. M.; JUSTI, R. S. A abordagem do DNA nos livros de biologia e química do ensino médio: uma análise crítica. Ensaio: pesquisa em educação em ciências, Belo Horizonte, v. 6, n. 1, p. 35-48, 2004.

GALL, M. D.; GALL, J. P.; BORG, W. R. Educational research: an introduction. Boston: Pearson Education, 2003.

JOHNSEN, E. B. Libros de texto en el calidoscopio: estudio crítico de la literatura y la investigación sobre los textos escolares. Barcelona: Ediciones Pomares-Corredor, 1996.

KETELE, J.-M.; ROEGIERS, X.; BRITO, C. A. Metodologia da recolha de dados: fundamentos dos métodos de observações, de questionários, de entrevistas e de estudo de documentos. Lisboa: Instituto Piaget, 1993.

LEITE, L. Heat and temperature: an analysis of how these concepts are dealt with in textbooks. European Journal of Teacher Education, Abingdon, v. 22, n. 1, p. 75-88, 1999.

LEITE, L.; AFONSO, A. S. Portuguese school textbooks' illustrations and students' alternative conceptions on sound. In: PINTO, R.; SURINACH, S. (Ed.). Proceedings of the International Conference Physics Teacher Education Beyond 2000. Paris: Elsevier, 2001. p. 167-170.

MARTÍNEZ-GARCIA, M. V.; GIL-QUÝLEZ, M. J.; OSADA, J. Genetic engineering: a matter that requires further refinement in Spanish secondary school textbooks. International Journal of Science Education, London, v. 25, n. 9, p. 1148-1168, 2003.

MARTINEZ LOSADA, C. et al. Enseñar ciencias en educación primaria: ¿qué tipos de actividades realizan los profesores? In: MARTINEZ LOSADA, C.; GARCÍA-BARROS, S. (Ed.). La didática de las ciencias: tendencias actuales. A Coruña: Universidade da Coruña, 1999. p. 199-210.

MEGID NETO, J.; FRACALANZA, H. O livro didático de ciências: problemas e soluções. Ciência \& Educação, Bauru, v. 9, n. 2, p. 147-157, 2003.

MORGADO, J. C. Manuais escolares: contributo para uma análise. Porto: Porto Editora, 2004.

PEDRANCINI, V. D. et al. Ensino e aprendizagem de biologia no ensino médio e a apropriação do saber científico e biotecnológico. Revista Electrónica de Enseñanza de las Ciencias, Vigo, v. 6, n. 2, p. 299-309, 2007. 
PEDROSA, M. A.; LEITE, L. Educação em ciências e sustentabilidade na Terra: uma análise das abordagens propostas em documentos oficiais e manuais escolares. In: CONGRESO DE ENSINANTES DE CIENCIAS DE GALICIA, 18., 2005, Ribadeo. Actas... Ribadeo: Asociacion dos Ensinantes de Ciencias de Galicia, 2005. 01 CD-ROM.

PORTUGAL. Ministério da Educação. Decreto-lei no 47/2006 de 28 de Agosto. Diário da República, Lisboa, n. 165, 2006. $1^{\circ}$ Série, p. 6213- 6218.

POZZER, L. L.; ROTH, W. M. Prevalence, function and structure of photographs in high school biology textbooks. Journal of Research in Science Teaching, Hoboken, v. 40, n. 10, p. 1089-1114, 2003.

REIS, P. Controvérsias sócio-científicas: discutir ou não discutir? Percursos de aprendizagem na disciplina de Ciências da Terra e da Vida. 2004. 488 f. Tese (Doutoramento em Educação) - Faculdade de Ciências, Universidade de Lisboa, Lisboa, 2004.

ROSEMAN, J. E.; STERN, L.; KOPPAL, M. A method for analyzing the coherence of high school biology textbooks. Journal of Research in Science Teaching, Hoboken, v. 47, n. 1, p. 47-70, 2010.

SANTOS, M. E. N. V. M. Educação pela ciência e educação sobre ciência nos manuais escolares. Revista Brasileira de Pesquisa em Educação em Ciências, Belo Horizonte, v. 4, n. 1, p. 76-89, 2004.

SANTOS, M. E. N. V. M. A cidadania na "voz" dos manuais escolares: o que temos? o que queremos? Lisboa: Livros Horizonte, 2001.

SANTOS, E. M. V. Ensino de ciências e literacia científica: o caso dos organismos geneticamente modificados. 2006. 163 f. Dissertação (Mestrado em Comunicação e Educação em Ciência) - Secção Autónoma de Ciências Sociais, Políticas e Jurídicas, Universidade de Aveiro, Aveiro, 2006.

SNYDER, V. L.; BROADWAY, F. S. Queering high school biology textbooks. Journal of Research in Science Teaching, Hoboken, v. 41, n. 6, p. 617-636, 2004.

STERN, L.; ROSEMAN, J. E. Can middle school science textbooks help students learn important ideas?: findings from project 2061's curriculum evaluation study: life science. Journal of Research in Science Teaching, Hoboken, v. 41, n. 6, p. 538-568, 2004. 
Dourado, L.; Matos, L.

Anexo A. Lista de manuais de ciências naturais, $9^{\circ}$ ano, publicados em Portugal e utilizados neste estudo

M1 BARROS, A.; DELGADO, F. Planeta Terra. Carnaxide: Santillana-Constância, 2008.

M2 CAMPOS, C.; DELGADO, Z. 9CN. Lisboa: Texto Editores, 2008.

M3 DEUS, H. M.; ALBUQUERQUE, F. Geovida. Lisboa: Lisboa Editora, 2008.

M4 FRANCO, N.; FRANCO, E.; BORGES, M. Bios. Porto: Edições Asa, 2008.

M5 MESQUITA, A. et al. Planeta vivo 9. Porto: Porto Editora, 2008.

M6 MOTTA, L.; VIANA, M. A. Bioterra 9. Porto: Porto Editora, 2008.

Artigo recebido em 24/09/13. Aceito em 07/05/14. 